\title{
O USO DO TERRITÓRIO NO BRASIL NA PERSPECTIVA DE UMA REVOLUÇÃO, MAS QUAL REVOLUÇÃO? A NECESSIDADE DE UMA PEDAGOGIA POLÍTICA
}

\author{
EL USO DEL TERRITORIO EN BRASIL EN LA PERSPECTIVA DE UNA REVOLUCIÓN, \\ ¿PERO QUÉ REVOLUCIÓN? LA NECESIDAD DE UNA PEDAGOGÍA POLÍTICA
}

\section{THE USE OF TERRITORY IN BRAZIL IN A REVOLUTION PERSPECTIVE, BUT WHAT REVOLUTION? THE NEED FOR A POLITICAL PEDAGOGY}

DOI: http://dx.doi.org/10.9771/gmed.v12i3.37316

Cláudio Jorge Moura de Castilho ${ }^{1}$

\begin{abstract}
Resumo: O uso do território no Brasil tem acontecido visando tornar o seu espaço mais fluido à realização dos interesses do capital, criando e agravando as desigualdades e injustiças sociais. O objetivo do artigo é analisar o processo de uso do território na perspectiva de uma revolução calcada nas condicionantes histórico-geográficas brasileiras atuais. O método utilizado é o materialismo histórico-dialético, o qual teve suporte de revisão bibliográfica, observação de campo e escuta de pessoas das classes dominadas e oprimidas. A conclusão geral é de que uma revolução é um processo muito mais complexo do que se tem pensado e buscado executar a partir da academia.
\end{abstract}

Palavras chave: Território usado. Práxis. Movimento histórico. Transformação socioterritorial. Pedagogia política do território.

Resumen: El uso del teritorio en Brasil ha sucedido haciendo su espacio quedarse más fluido para la realización de los intereses del capital, creando y agravando las desigualdades e injusticias sociales. El objetivo del artículo es analisar el proceso de uso de la tierra en función de las condiciones históricas y geográficas brasileñas actuales. El método utilizado es el materialismo histórico y dialectico, que tuvo el apoyo de revisión bibliográfica, observación de campo y escucha de personas de las clases dominadas y oprimidas. La conclusión general alcanzada es que una revolución es un proceso más complejo de lo que se ha pensado e intentado llevar a cabo desde la academia.

Palavras claves: Teritorio usado. Práxis. Movimiento histórico. Transformación socioterritorial. Pedagogía política do teritório.

Abstract: The use of territory in Brazil has occurred for improving the space's fluidity towards the capital interests achievement, raising and growing up social inequality and injustice. The purpose of the paper is to analyze thel use of territory in Brazil in a revolution perspective based on the Brazilian historical-geographical conditions. The method chosen was the historical-dialectical materialism based on the bibliographic review, field visit and listening to people from dominated and oppressed classes. The general conclusion reached was that a revolution is a process much more complex than it has been thought and sought to carry out from the academy.

Keywords: Used territory. Práxis. Historical movement. Socioterritorial changing. Political pedagogy of territory.

Um espectro ronda a Europa: o espectro do comunismo. Todas as potências da velha Europa estão se unindo numa Santa Aliança para encurralá-lo... (MARX e ENGELS, 1987, p. 25)

\section{Introdução}

Esta reflexão teórico-empírica fundamenta-se na perspectiva de que a concretização da revolução social acha-se intrinsecamente vinculada à mudança do uso do território, na medida em que o território não 
constitui um epifenômeno; mas, meio e condição à realização das relações sociais em qualquer momento da história, razão pela qual ele é permanentemente usado pela sua sociedade.

O objetivo geral deste escrito é analisar o processo de uso social do território no Brasil na perspectiva de uma revolução calcada em condicionantes histórico-geográficas e ideológicas inerentes a uma dada sociedade e num dado momento da história. O emprego do artigo indefinido "uma" - e não do artigo definido "a" - deve-se ao fato de que não existe um caminho único e estanque da revolução no tempoespaço como uma fórmula mágica.

Sem a intenção direta de apontar um caminho a ser seguido, optou-se pela incursão na história com a finalidade de, retomando a discussão acerca da necessária revolução, captar a dinâmica do seu acontecer no tempo-espaço ressaltando o que é pertinente à constituição de projetos revolucionários efetivamente vinculados às necessidades reais da coletividade brasileira. Isso se justifica pelo fato de que não dá mais para viver em um mundo no qual a exploração dos homens e das mulheres através das suas relações de trabalho e a destruição da natureza natural foram banalizadas.

A história serve para levar-nos às origens e, portanto, às causas dos problemas vigentes para se compreender o presente visando não se repetir os erros do passado; mas, concomitantemente, para, demonstrando a permanência dos referidos erros no tempo-espaço, desmanchar a ideologia hegemônica na perspectiva de, mediante ações pedagógicas, retomar as promessas do processo civilizatório.

A quem caberia essa tarefa senão à ciência, mas não a ciência tradicional comprometida com a manutenção do establishment. Criticando o papel dos intelectuais tradicionais na reprodução das relações capitalistas, Gramsci (1989, p. 8) acentuou que, com base na lição do engajamento político dos autores do Manifesto do Partido Comunista, faz-se necessária a formação e atuação de um novo intelectual cujo modo de ser consiste no imiscuir-se ativamente na vida prática como organizador e dirigente.

A ciência deve cumprir com os seus papéis ético e político, ou seja, considerar o que está acontecendo nas escalas do tempo-espaço da sociedade, destacando e refletindo sobre perspectivas concretas que valorizem e respeitem a diversidade da coletividade territorial; e superar a análise científica dos fatos, engajando-se nos processos de lutas sociais ${ }^{2}$ vislumbrando o dever ser. Tal como o precursor maior das ideias revolucionárias, Karl Marx, nos ensinou, a ciência deve preocupar-se com o estado em que se encontra a realidade existencial humana para, através da conexão dos fatos como uma totalidade contraditória e conflituosa num movimento histórico permanente, vislumbrar o que deverá acontecer considerando o que existe no mundo como potencialidade, mas que ainda não se realizou.

$\mathrm{Na}$ dialética constante entre permanência e superação, a obra do referido pensador elucidou que a verdade é histórica, demonstrando que, como forma histórica, o capitalismo pode ser superado. Daí a necessidade de estudá-lo, considerando as suas condicionantes temporais e apontando os obstáculos que impedem a formação de uma nova sociedade. Em síntese, o capitalismo é um modo de produção que caracteriza e organiza a sociedade em torno do mercado, o qual, sob a lógica da troca mercantil, torna-se o centro da sociedade que está dividida em classes sociais, estabelecendo, agravando e mantendo as desigualdades inerentes à perversidade deste modo de produção. Mas, o mercado apresenta-se, 
ideologicamente, como uma instituição neutra e como oportunidade à realização das trocas justas, prometendo a liberdade e igualdade que nunca se realiza.

Diante de tal achado, diferentemente do que ainda se diz hoje, Marx não pretendeu inventar uma sociedade ideal - inclusive, ele criticou o "socialismo utópico" - como a comunista; mas defendeu as promessas não realizadas pelo mercado. Neste sentido, somente a abolição do capitalismo conseguiria emancipar a sociedade, por meio de uma postura teórico-prática crítica sujeita a revisões acerca da mudança efetiva com base nas condicionantes histórico-geográficas.

Além destas considerações, estruturou-se o artigo para apresentar: os pressupostos teóricos da reflexão (primeira seção); a metodologia escolhida (segunda seção); o uso do território no Brasil, dificultando a concretização de uma revolução efetiva com relação à ordem hegemônica e, contraditoriamente, destacando o que acontece na realidade que pode auxiliar na elaboração da construção de uma pedagogia política para um outro mundo (terceira seção); e conclusões (quarta e última seção).

\section{Pressupostos}

O sentido da história do capitalismo acha-se associado à dinâmica do modo de ser (produçãocirculação-distribuição-consumo) e pensar (ideologias que norteiam o conjunto de ações) que, dialeticamente, influenciam na dinâmica dos aconteceres sociais a partir dos territórios do mundo, concretizando preponderantemente os interesses hegemônicos. Há cinco séculos, o modo capitalista de ser e pensar foi imposto ao mundo de maneira violenta, perversa e fatal, apresentando-se através da elaboração e propagação, como escrevera Santos (2000), de fábulas utilizadas, ideologicamente, para estabelecer consenso social visando mascarar a perversidade inerente à lógica do seu acontecer histórico-geográfico.

O uso do território, sob o modo capitalista de ser e pensar, acontece para continuar atendendo os interesses econômicos. Por isso, segundo Santos e Silveira (2001), muito além do território per se, o que é importante para a pesquisa e o ensino da geografia é ocupar-se, concomitantemente, com o território usado, na medida em que a forma através da qual este território apresenta-se indica a natureza da sua sociedade e suas diversas possibilidades de futuro.

A ideia de revolução como potencialidade efetiva de transformação social trata-se de um processo de mudança das relações sociais capitalistas de ser e pensar que sustentam os diversos usos dos territórios que fazem parte do mundo. Durante o século XIX, através de profunda reflexão teórica acerca do funcionamento do referido modo capitalista, a filosofia defendeu a ideia da revolução como o próprio movimento histórico como processo permanente de luta de classes. Para Friedrich Engels, "Foi precisamente Marx quem primeiro descobriu a grande lei da marcha da história [...] segundo a qual todas as lutas históricas que se desenvolvem [...] são, na realidade, apenas a expressão mais ou menos clara de lutas entre classes sociais". (MARX e ENGELS, 1987, p. 12-13)

Acredita-se que a natureza de classe faz parte dos movimentos sociais bem como de ações de protestos, revoltas, mobilização e qualquer outra reação das classes sociais dominadas e oprimidas diante da perversidade do modo capitalista de ser e pensar. Após conquistarem o poder, as classes dominantes e 
opressoras continuaram sendo aquelas que, norteadas pela racionalidade técnico-instrumental capitalista, colocaram os interesses econômicos acima de tudo, usando o território como meio e condição à reprodução dos seus interesses. Por isso que, segundo Harvey (2013), onde quer que se ache presente, o capital transforma em riqueza tudo o que encontra em seu caminho, negando de imediato o que não lhe interessa.

Muito além da sua dimensão objetiva, o conjunto das ações dos referidos interesses, segundo ainda Marx e Engels (1987, p. 30), "dilacerou o céu de sentimentalismo que envolvia as relações de família e reduziu-as a simples relações monetárias", bem como todas as demais relações humanas transformandoas em estratégias para a acumulação e reprodução de riquezas, ameaçando a vida humana na Terra e, por seu turno, a própria vida dos detentores do capital, o que nos remete à ideia da racionalidade puramente econômica como algo louco denunciado por Harvey (2018). Fazendo valer os seus interesses, apropriandose do Estado como "comitê para gerir os negócios comuns de toda a classe burguesa", o conjunto dos interesses dominantes e opressores transformou a dignidade pessoal em mero valor de troca: "Do médico, do jurista, do sacerdote, do poeta, do sábio, do homem de ciência, fez seus servidores assalariados. (MARX e ENGELS, 1987, p. 30)

De acordo com Gramsci (1989, p. 11), exercendo funções organizativas e conectivas a fim de fazer valer os interesses das classes dominantes e opressoras, os intelectuais tradicionais, como "comissários" dos interesses acima destacados, contribuem ao exercício das funções subalternas pelo consenso espontâneo das massas e pelo aparato de coerção estatal que assegura a disciplina.

Os interesses das classes dominantes e opressoras conseguem formular e impor uma ideologia eficaz à sua reprodução na história, subordinando drasticamente as classes dominadas e oprimidas. Estas, quando cooptadas pelas fábulas - do desenvolvimento, do pleno emprego, da inclusão social, etc. - criadas e propagadas para ludibriá-las, acabam reforçando os interesses hegemônicos vigentes.

Ressalta-se que "[...] toda a História tem sido uma história [...] de lutas entre as classes exploradas e as classes exploradoras, entre as classes dominantes e as classes dominadas, nos diferentes estágios do desenvolvimento social ...”. (MARX, 1987, p. 13) Acredita-se que a oposição e o antagonismo entre as classes continuam no mundo de hoje, muito embora se tenha dito o contrário. Na realidade, houve mudanças na forma da estrutura de classes na medida em que a complexidade da composição da estrutura das classes aprofundou-se ainda mais.

Entre a burguesia e o proletariado, surgiram segmentos sociais denominados de classes médias, dificultando a compreensão do funcionamento da estrutura social e da permanência da luta de classes na sociedade capitalista. Souza (2017) leva-nos a compreender que as classes médias fazem parte da classe trabalhadora, do que se chamava antes de proletariado; mas que se recusa a aceitar-se como tal e que, por ter acesso a renda, formas culturais e padrão de vida mais elevados proporcionando-lhes privilégios, pensam que são classe dominante, fazendo tudo para parecê-lo. Este desdobramento da estrutura social, pela estratégia da cooptação, fragmentou ainda mais o grupo das classes dominadas e oprimidas, prejudicando a compreensão da complexidade da estrutura social e a união dos trabalhadores para o enfrentamento da luta de classes. 
A fragmentação social das classes dominadas e oprimidas tem a ver com a posição de cada uma no mercado de trabalho: entre os/as trabalhadores/as vinculados/as ao circuito superior e ao circuito inferior da economia dos diversos territórios do mundo, dificultando a união e solidariedade entre os membros das classes revolucionárias.

Fundamentando-se nos elementos analisados deste acontecimento histórico, defendendo que somente a democracia social seria capaz de enfrentar a reação feudal burguesa dominante, Marx (1986) acentuou a necessidade do proletariado urbano adquirir a consciência de sua real força social para organizarse e impor-se como classe hegemônica. Enfim, “[...] era preciso dotar o proletariado de uma teoria capaz de fornecer-lhe os meios para uma ação consciente própria [...]. Daí [...] Deixava de ser uma classe em si, para se transformar numa classe para si”. (MARX, 1986, p. 13)

Acredita-se que a lógica do processo de autoconscientização das classes dominadas e oprimidas, sobre sua situação de classe, continua relevante ainda hoje como atividade pedagógica, na medida em que ainda se vive sob os imperativos do modo capitalista de ser e pensar. A exploração do trabalho e dos bens da natureza natural, visando ao crescimento econômico a todo custo para a geração de riquezas ainda constituem a base do capitalismo.

As formas de conquistar o consenso, inclusive das classes dominadas e oprimidas, para a reprodução das relações capitalistas de ser e pensar tornaram-se muito eficazes, notadamente pela formulação e difusão das fábulas do desenvolvimento, da inclusão social e da cidadania, mascarando a perversidade do mercado. A fragmentação social ocorreu para dificultar o entendimento da natureza da estrutura social, tornando a cooperação à mudança algo muito mais complexo do que já o era no século XIX.

Do ponto de vista do uso do território, os grandes centros da produção industrial - que, antes, reuniam os/as trabalhadores/as, proporcionando-lhes, contraditoriamente, o ambiente propício à crítica das relações de trabalho pela discussão dos problemas comuns e reflexão sobre alternativas diferentes de trabalho e vida - foram desmanchados pela introdução de táticas inerentes à acumulação flexível. O que repercute negativamente na força do sindicalismo e nas possibilidades de ampliação e manutenção das conquistas obtidas ao longo da sua história de lutas.

Entretanto, sempre houve e haverá brechas que, se bem aproveitadas, podem tentar construir algo novo em termos de uso de território e, por sua vez, de sociedade, muito embora nunca se esteja livre das reações contrarrevolucionárias da parte das classes dominantes e opressoras capazes de desviarem e deturparem os objetivos dos projetos revolucionários. A primeira experiência histórica de um governo operário, que expressou nítido caráter de classe, foi a da Comuna de Paris a qual inaugurou uma série de novidades demonstrando uma linha de governo que usou o território conquistado conforme às necessidades dos/as trabalhadores/as da França.

Esta experiência mostrou-nos que somente as classes dominadas e oprimidas no Poder terão condições efetivas para construir uma sociedade que também garanta os seus direitos ao território, ou seja, à sua sociedade, uma vez que são os/as trabalhadores/as que constroem as sociedades: "Os homens fazem a sua própria história, mas não a fazem segundo a sua livre vontade...” (MARX, 1987, p. 15). A revolução 
sempre deve ser pensada, refletida e praticada com os pés no chão, estando-se preparados para o enfrentamento de qualquer adversidade, inclusive tendo que bater retirada dos campos de luta politicamente estabelecidos, sobretudo em momentos da história em que as forças contrarrevolucionárias acham-se bastantes fortes.

A luta social não pode restringir-se a um só território, ela tem que ultrapassar a escala local do seu acontecer histórico-geográfico, visto que a revolução não se concretiza em um só lugar. Ao contrário, assim como o fizeram as classes dominantes e opressoras no século XVIII, as classes dominadas e oprimidas têm que fazer o mesmo, isto é, expandir seus interesses materiais e imateriais. Paralelamente, tem-se que procurar neutralizar as reações contrarrevolucionárias, as quais também são alimentadas por forças externas ao território.

Marx (1986) destacou outras lições da referida experiência: ao tomar o Estado, a classe operária não pode governar utilizando-se dos mesmos aparelhos de Estado burguês; ela tem que desconfiar dos seus mandatários e funcionários, demitindo-os se necessário; a escolha dos cargos públicos, inclusive dos magistrados e dos juízes, deve acontecer pelo sufrágio universal e os salários devem ser pagos com valores iguais aos dos demais trabalhadores e sem nenhuma prerrogativa de vitaliciedade; democratizar o acesso às instituições de ensino, liberando-as dos Poderes da Igreja e do Estado; e manifestar seu entusiasmo pela República democrática. $\mathrm{O}$ “[...] Estado não é mais do que uma máquina para a opressão de uma classe por outra [...]; e, no melhor dos casos, um mal que se transmite hereditariamente ao proletariado triunfante em sua luta pela dominação de classe". (MARX, 1986, p. 29)

Atualmente, ainda não se entendeu o verdadeiro sentido da ideia da ditatura do proletariado, problema causado pelas classes dominantes e opressoras para livrarem-se do sempre temido "espectro do comunismo que ronda o mundo". As classes dominadas e oprimidas, até quando se puder construir algo alternativo, devem utilizar-se do Estado - como um "mal necessário" - fazendo-o um instrumento para atender os seus interesses. Somente assim elas poderão concretizar a sua missão, a qual, como acentuara Marx (1986), não é a de "repetir o passado, mas de construir o futuro", e só elas podem fazê-lo porque somente elas conhecem suas reais necessidades: "Que aproveitem serena e resolutamente as oportunidades que lhes oferece a liberdade republicana para trabalhar na organização de sua própria classe” (MARX, 1986, p. 48)

Portanto, não se acredita que a verdadeira intenção de K. Marx e F. Engels era de instituir-se uma ditadura a exemplo da que implantou Stalin na ex-URSS e/ou defendida por marxistas ortodoxos sem nenhum respaldo na realidade histórico-geográfica. As teorias devem iluminar as mentes das pessoas que pensam o seu mundo, suscitando ideias e abrindo outras alternativas acerca das possibilidades de uso do território. Claro está que os pilares básicos que sustentam as relações capitalistas de ser e pensar têm que ser revistos e mudados. Porém, não se transforma uma realidade secular de uma hora para outra, pois sempre haverá fortes e eficazes resistências capazes de empreenderem reações violentas e esmagadoras.

Às vezes, projetos de reforma social tornam-se algo muito mais palpáveis para dar saltos no sentido da revolução. Neste sentido, a concretização do que está escrito e garantido legalmente como direitos adquiridos na Constituição da República Federativa do Brasil de 1988 - para o urbano, o rural, as 
populações tradicionais indígenas, quilombolas, pescadores/as e trabalhadores/as - constituem per se um primeiro passo à revolução.

Após conseguir tais conquistas, o que já se faz muito difícil em países como o Brasil, cujos movimentos sociais que as reivindicam sempre são negados e massacrados (CASTILHO, 2020), poder-seá prosseguir na luta pela construção de outro uso social do território. Um território que, construído como espaço do cidadão (SANTOS, 1987) no qual os/as dominados/as e oprimidos/as consigam ser mais e, ao mesmo tempo, formar um lugar forte (SANTOS, 1997) capaz de conquistar o que de fato lhes interessa.

\section{Metodologia}

Optou-se pelo materialismo histórico-dialético como método de abordagem, escolha que se fundamentou no fato de que o uso social do território no Brasil deve ser apreendido no âmbito da dinamicidade permanente do processo histórico do capitalismo, destacando suas contradições, suas tensões/seus conflitos, como uma totalidade complexa formada pela unidade dos contrários, a qual se movimenta permanentemente em algum sentido, o qual só mesmo a história pode apontar. Para Colturato e Massi (2019, p. 177-178), o pensamento histórico, dialético e materialista supera as dicotomias e faz da ciência uma prática social humana no âmbito de um contexto universal.

A revisão bibliográfica, observação de campo e escuta das classes dominadas e oprimidas nos seus próprios territórios foram os procedimentos utilizados. O primeiro levantou, na sua origem, as principais ideias acerca das possibilidades de transformação das relações capitalistas de ser e pensar. A observação do território destacou o que está acontecendo in loco como potencialidade ao vir a ser identificando as contradições da lógica do uso do território em países subdesenvolvidos, bem como penetrar nos territórios das referidas classes para, empaticamente, sentir os seus problemas. A escuta das pessoas, utilizando-se de entrevistas, proporcionou o reconhecimento do significado das palavras ditas, mas, por respeito e cautela, não se divulgou as identidades dos/das respondentes.

Optou-se pela consulta a três obras clássicas do precursor da teoria da revolução social no mundo moderno, Karl Marx, as quais constituem a espinha dorsal da discussão, pela sua permanência no tempo e mutatis mutandis pela sua pertinência para as discussões contemporâneas. Evitou-se o risco do exagero exaustivo do citacionismo infrutífero.

\section{O uso do território no Brasil}

A gente quer viver pleno direito

A gente quer é ter todo respeito

A gente quer viver uma nação

A gente quer é ser um cidadão...

(GONZAGUINHA, É, 1980)

Ao fazer-se presente, as relações capitalistas de ser instalaram fixos - engenhos, fazendas, plantações, vias de comunicação, portos com a infraestrutura necessária ao escoamento das commodities, vilas, etc. - no espaço geográfico do país com a finalidade de utilizá-los para favorecer à geração de riquezas a 
todo custo, dizimando povos indígenas, escravizando povos africanos e destruindo os elementos constituidores da natureza natural - vegetação, rios, solos, etc.

A história da formação territorial no Brasil tem-se calcado numa lógica segundo a qual o espaço continental era percebido como uma área vazia - sem história e sem natureza - que deveria ser, permanentemente, preenchida com os objetos necessários à produção de um território provedor das commodities demandadas pelo mercado mundial. Esta lógica de uso do território foi marcada pela violência e pelo desrespeito para com os ambientes encontrados no Novo Mundo, exercendo, como rugosidades perniciosas, influências nas ações pensadas, praticadas e defendidas nos dias atuais, hoje sob a hegemonia dos Estados Unidos, não obstante as mudanças ocorridas ao nível do acontecer das relações capitalistas no mundo.

Enquanto que, no seu evoluir, o capitalismo tornou-se, mais atraente para várias coletividades socioterritoriais do mundo, sob o manto de uma ideologia que mascara sua perversidade, o poder autoritário e patriarcal exercido pelas classes dominantes e opressoras locais foi determinante para a formação de um território exacerbadamente desigual e injusto.

A política do diálogo entre as classes sociais, inerente a qualquer sociedade democráticoparticipativa, sempre foi negada e, mesmo, em certa medida, proibida pelos Poderes instituídos, o que não quer dizer que as classes dominadas e oprimidas tenham baixado a cabeça diante da opressão. Ao contrário, sempre houve protestos, revoltas, mobilizações e mesmo movimentos sociais no curso da história da formação do território brasileiro. Entretanto, tais reações, segundo Castilho (2020), foram desconsideradas e massacradas, sem piedade, pelas classes dominantes e opressoras. Ressalta-se que o distanciamento social entre as referidas classes caracterizou a formação territorial do Brasil. Assim, “[...] as elites dirigentes [...] viveram sempre [...] sob o pavor pânico do alçamento das classes oprimidas. Boa expressão desse pavor pânico é a brutalidade repressiva contra qualquer insurgência e a predisposição autoritária do poder central, que não admite qualquer alteração da ordem vigente. (RIBEIRO, 2015, p. 20)

O pavor e a brutalidade das classes dominantes e opressoras para com os interesses e as reivindicações das dominadas e oprimidas permanecem no tempo-espaço não somente devido ao medo da perda dos privilégios seculares da parte das primeiras; mas, ao mesmo tempo, devido ao ódio das classes dominantes com relação às dominadas, cujas raízes acham-se fincadas na escravidão. Faz-se mister considerar o conceito de escravidão para entender a complexidade da natureza do processo de formação territorial do Brasil, sem o qual não se compreenderá a problemática territorial e, por sua vez, não se conseguirá superá-la. Com efeito, no Brasil, para Souza (2017, p. 40), “[...] a instituição que englobava todas as outras era a escravidão [...]. Nossa forma de família, de economia, de política e de justiça foi toda baseada na escravidão", embora a história oficial não a reconheça.

Na história de expansão das relações capitalistas de ser e pensar no Brasil, notou-se a permanência da tendência, notadamente durante suas fases cíclicas de neoliberalismo (HARVEY, 2005), à alienação dos diversos territórios, natural e historicamente produzidos, fazendo do território o lugar favorável à acumulação de capitais os quais, na cidade e no campo, expressam-se pelo que se tem chamado (CASTILHO, 2019) de Complexo Fundiário, Imobiliário, Comercial, Financeiro (CFICF). Esta tendência 
faz-se mais forte em territórios que, historicamente, inseriram-se e/ou estão para inserirem-se no processo de mundialização.

Na condição de espaços em que a escravidão constituiu a base da sua formação, a emergência de qualquer alternativa de uso do território que se contraponha aos impostos pelos imperativos da racionalidade técnico-instrumental capitalista cujo escopo maior é homogeneizar o espaço visando à sua valorização preponderantemente capitalista, torna-se uma tarefa muito difícil. Seguindo o sentido desta valorização, o espaço brasileiro tem sido usado para se produzir territórios visando garantir, preponderantemente, a fluidez necessária para facilitar a realização dos fluxos econômicos. Na cidade, são os fixos e fluxos implantados no território visando à formação de espaços residenciais de alto luxo, de centros empresariais, turismo, lazer e consumo, facilitados e articulados pelas novas tecnologias, que determinam a urbanização (Figura 1).

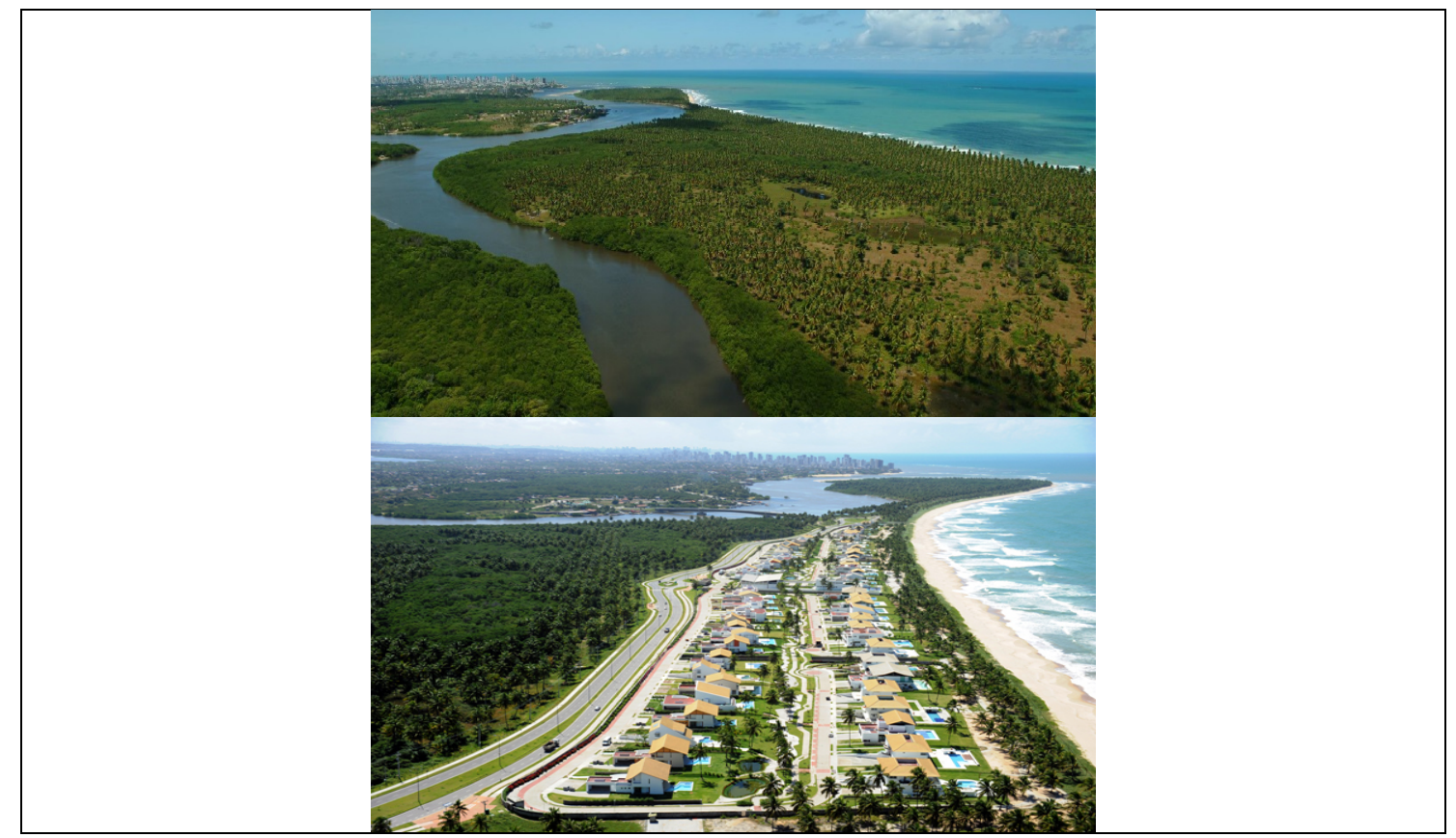

Figura 1 - Destruição de territorialidades em porção costeira da área metropolitana do Recife, estado de Pernambuco. Fonte: Pontes, 2017.

No campo, os fixos e fluxos implantados no território visam a expansão, notadamente, das atividades atinentes ao agronegócio as quais, autoritária, violenta e desrespeitosamente, passam por cima do conteúdo territorial representado pelos bens naturais e culturais (Figura 2) tais como: biomas, populações indígenas e quilombolas.

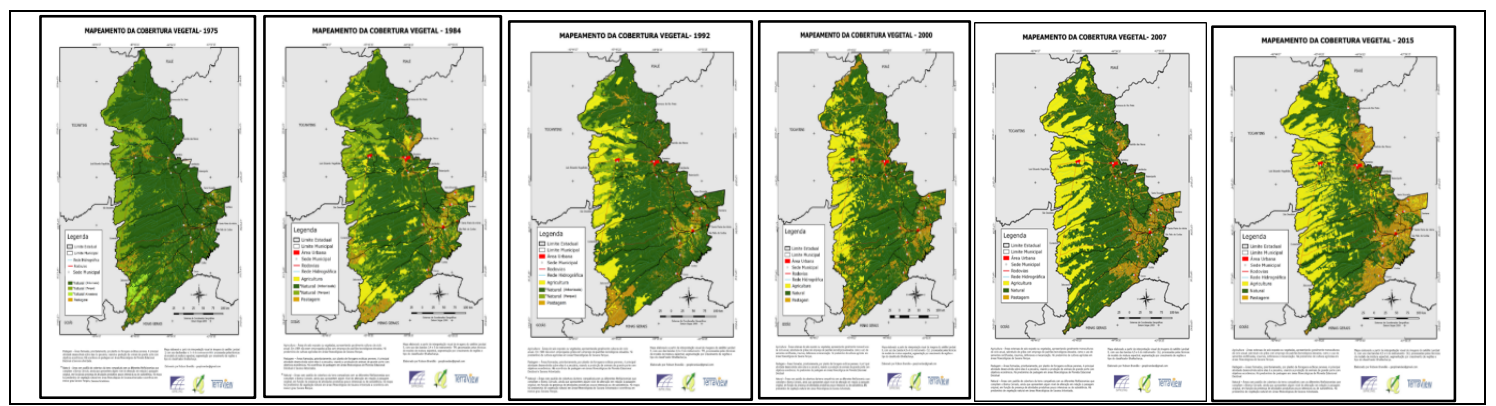

Figura 2 - Destruição do bioma cerrado no Oeste Baiano. Fonte: Brandão, 2017.

Nota-se que, de 1975 a 2015, no Oeste da Bahia, os cerrados foram significativamente reduzidos, ou melhor, destruídos pela implantação do agronegócio; enquanto que, na cidade, neste início de século 
XXI, observa-se que a urbanização destruiu a natureza de uma área de grande valor ambiental para construir um território fluido para fazer valer os interesses do CFICF. Estes dois tipos de uso do território são impostos e introduzidos, violenta, perversa e autoritariamente, pelos agentes alienígenas ligados ao CFICF fazendo do Estado um comitê para gerir os interesses comuns das classes dominantes e opressoras, buscando, pela ideologia, alienar a diversidade ambiental local, impedindo o acontecer histórico de formas outras de uso do território.

Entretanto, como a história constitui um processo contraditório que está em permanente movimento, as classes dominadas e oprimidas, aproveitando-se de brechas deixadas e, ao mesmo tempo, criando-as, rebelam-se e resistem. Isso, sobretudo, quando se sentem ameaçadas de remoção pelas ações das classes que buscam apoderar-se deles, geralmente com o apoio do Estado, para realizar os seus respectivos empreendimentos fundiários, imobiliários, comerciais e financeiros (CASTILHO, 2019), sustentados na fábula de que a urbanização e o agronegócio propiciarão o desenvolvimento regional.

Quando as classes dominadas e oprimidas levantam-se contra os referidos projetos, imediatamente, as classes dominantes e opressoras reagem contra as suas ações de mobilização, utilizandose, no âmbito da ideologia, de táticas de criminalização, negação e massacre das referidas mobilizações, o que ocorre, geralmente, com o apoio do aparelho repressor do Estado, evidenciando a continuidade da luta de classes na história contemporânea.

Admite-se que, no Brasil, ainda não há terreno para a realização da revolução tal como teorizada, o que se deve, notadamente, a várias razões a saber: as classes dominantes e opressoras, como "elites do atraso", exercem um poder implacável que controla todas as instâncias da sociedade, negando, massacrando e criminalizando qualquer movimento social; as classes dominadas e oprimidas, fragmentadas como se acham e imbuídas pelas promessas do mercado, não conseguem, ainda, dar saltos além da conquista dos direitos mínimos à sua existência social; territórios do trabalho foram progressivamente dispersos no campo e na cidade, dificultando a reunião das trabalhadoras e dos trabalhadores; e as condicionantes históricas tornaram-se tão complexas que as classes dominadas e oprimidas não conseguirão entendê-la em sua totalidade.

Mesmo quando, em determinados contextos de mais liberdade e protagonismo, as classes dominadas e oprimidas obtêm êxitos em termos de conquistas dos seus direitos mínimos; logo em seguida, as classes dominantes e opressoras - movidas pelo ódio aos pobres, aos negros, aos indígenas, etc. -, reorganizam-se para reagirem aos avanços sociais visto que as segundas não aceitam de maneira nenhuma a convivência social com as primeiras.

O ódio "dos de cima" com relação "aos de baixo" é tão forte que qualquer forma de uso do território pelos "de baixo" é refutada e destruída, razão por que estes sempre se acham ameaçados. No campo, os territórios dos indígenas e quilombolas são destruídos e/ou deixados em estado de abandono pelas políticas públicas até que seus moradores morram à míngua para, depois, apropriarem-se das terras. $\mathrm{Na}$ cidade, as favelas e/ou palafitas, sobretudo quando não há resistências, são removidas para, em seus respectivos lugares, implantar-se o conjunto de fixos necessários à realização dos fluxos econômicos de interesse do CFICF. 
Contraditoriamente, os empecilhos à mudança social não constituem impedimentos absolutos, fazendo valer apenas os interesses hegemônicos. Tais interesses também são negados e, portanto, encontram resistências da parte das classes dominadas e oprimidas quando estas se acham pertencidas, como escreveu Santos (1997), a territórios como lugares fortes; o que demonstra que, por mais implacável que seja, o capital não acontece tal como desejam e imaginam os seus corifeus, razão pela qual tem que abrir brechas para negociações.

Em Recife, por exemplo, muitos territórios conquistaram, sob pressão social dos seus moradores, acesso a obras de infraestrutura urbana e a bens de consumo coletivo (desde meados do século XX); posteriormente, ao sentirem-se ameaçados pelos interesses do CFICF, várias territorialidades conquistaram a garantia da sua permanência no território contra as investidas desses interesses ao pressionarem o executivo local para inserir a lei das Zonas Especiais de Interesse Social (ZEIS) na Lei de Uso e Ocupação do Solo (LUOS), em 1983; as Comissões de Urbanização e Legalização (COMUL) como instrumentos de participação do Plano de Regularização das Zonas Especiais de Interesse Social (PREZEIS), em 1987, e o Orçamento Participativo, ao início dos anos 2000 sob administrações públicas do Partido dos Trabalhadores (PT), constituíram formas de pressionar o Estado visando à participação na gestão urbana; as diversas experiências de mobilização territorial de resistência à expulsão; e os movimentos de ocupação de terras no campo (MST) e na cidade (MTST), têm sido algumas das formas estabelecidas pelos "de baixo" visando à conquista do seu direito ao território.

O que mobiliza a maioria dos homens e das mulheres nas lutas acima elencadas não é a defesa de uma sociedade radicalmente diversa da capitalista, mas o desejo da sua inclusão social no território ocupado em que está presente com sua família, fazendo valer os direitos garantidos na legislação para os territórios situados nos meios urbanos e rurais. A conquista desses direitos possibilita formas de mudança, muito embora não sejam aquelas defendidas pelo pensamento ortodoxo.

O conteúdo da maioria das falas coletadas, nos territórios de existência ${ }^{3}$, reforça o que se acabou de colocar: "Nossos pais e avós lutaram pra ficar aqui, aqui a gente nasceu, casou e ficou também [...] agora a gente quer esgoto, saúde, educação, pra viver bem” (Moradora de assentamento popular no bairro Casa Amarela); "A gente quer ficar onde a gente mora desde que nasceu” (Moradora de uma favela no bairro Ipsep); "Nós somos agora donos desse lugar e ninguém tira a gente daqui”" (Ocupante de imóvel no centro do Recife); "A gente quer água encanada, esgoto e uma usina de reciclagem de lixo...”; “[...] a Prefeitura botou nós aqui, tudo bem, nós tem nossa casa, agora queremos trabalho porque sem trabalho não podemos comprar nada [...] nem mesmo pagar as contas de luz que chega" (Morador removido para um conjunto habitacional construído), dentre tantas outras falas cujo conteúdo vai na mesma direção.

A mudança territorial, para as pessoas escutadas deverá acontecer a partir do momento em que tiverem acesso a bens e serviços de consumo coletivo (saúde, educação, etc.), à infraestrutura urbana e ao trabalho, fazendo valer, como pensou Santos (1987), seu direito ao entorno, como passo ao direito à cidade (LEFEBVRE, 1968). As palavras mais pronunciadas durante a realização das entrevistas indicam o que se espera em termos de mudança (Figura 3). 


\section{HABITAÇÃO PERMANECER NO TERRENO ÁGUA E ESGOTO TRABALHO \\ SAÚDE \\ EDUCAÇÃO \\ ESCRITURA DA CASA}

Figura 3 - Palavras mais pronunciadas nas entrevistas. Fonte: pesquisa de campo realizada em 2019. Nota: o tamanho das letras indica a intensidade que cada palavra foi pronunciada.

O fato de começarem a fazer a leitura do seu mundo, pronunciando palavras sobre sua existência e problematizando-o, segundo Freire (2019), constitui per se algo que leva as classes dominadas e oprimidas a entenderem a sua condição e o seu papel neste mundo.

Acredita-se que o acesso, primeiramente, aos direitos sociais constitui um ponto de partida na perspectiva da revolução, visto que para mudar a sociedade é preciso, antes de tudo, participar dela e, ao mesmo tempo, entender o seu funcionamento em sua totalidade. Os/as entrevistados/as não defenderam outro modo de produção, senão um território que capaz de reunir as condições necessárias para uma sociedade mais justa e livre. Mas o que a ciência deve fazer neste momento?

Apoiar a luta pela conquista dos direitos sociais em uma sociedade tão desigual e injusta como a brasileira constitui ideia e prática revolucionária. Aperfeiçoando e atualizando as teorias capazes de sustentar o ir além da realização dessa luta, suscitando o desenvolvimento dos meios de ações conscientes e perseverantes da necessidade de superar, segundo Marx e Engels (1987, p. 68-69), o nível da formação da "classe em si", chegando ao da "classe para si".

Faz-se mister reconhecer que a mudança não constitui tarefa fácil, linear e rápida. Ela é muito difícil na prática e no pensamento. Há uma série de armadilhas nas trilhas a serem percorridas, razão pela qual se tem que ficar atentos.

Nota-se que se delineia um conjunto de perspectivas de pensar e praticar o mundo capaz de, como uma pedagogia política, vislumbrar outras formas de usar o território como suporte e meio de uso social do território que também lhes beneficie visando garantir o ser mais em um mundo tão difícil, cheio de armadilhas, mas, concomitantemente pleno de possibilidades para inovação e criatividade em termos da existência humana na Terra.

\section{Conclusões}

O uso social do território no Brasil, acha-se longe de uma situação que possa, ao nível da aparência, suscitar uma revolução sob os parâmetros teórico-empíricos colocados pelos primeiros pensadores acerca de um processo revolucionário sob o contexto do capitalismo, os quais ainda são pertinentes para a reflexão sobre o vir a ser a partir do mundo atual. 
Isso não inviabiliza o acontecer de processos que podem apontar para uma revolução quanto ao uso do território no Brasil, na medida em que, como a realidade histórico-geográfica acha-se em permanente movimento, engendrando contradições e conflitos no âmbito da totalidade, refazendo-se continuamente em função da dinâmica das condicionantes do tempo no espaço, vislumbra-se um conjunto de ações que, de certa feita, estão preparando o futuro.

A retomada da discussão sobre a necessidade de pensar a transformação do uso territorial como fundamental para a construção de uma sociedade diferente da que, autoritária e violentamente, se nos impõem constitui um passo relevante no sentido aqui discutido.

Tendo em vista que teoria e prática - como práxis - constituem dimensões inseparáveis do processo histórico, a retomada da referida discussão, com base no pronunciamento pelo próprio povo de palavras sobre o seu mundo e do engajamento da ciência nesse processo, possui como meta fundamental munir as classes dominadas e oprimidas de uma prática consciente no mundo.

Aprendendo com os territórios vividos que o processo revolucionário é muito mais complexo do que se pensa na academia, chega-se à conclusão de que, antes de buscar executar mundos imagináveis fora dos territórios concretamente vividos, urge dar suporte e legitimidade às reivindicações dos movimentos sociais, na cidade e no campo, pelos direitos sociais adquiridos e garantidos pela Carta Magna, tais como os direitos: à habitação, ao saneamento, ao território ocupado, ao trabalho, à saúde, à educação, à posse da terra, etc.

Faz-se necessário considerar o pensamento e a reflexão acerca de projetos outros de uso do território que, efetivamente, garantam-lhes a manutenção dos direitos adquiridos para não se sentirem mais ameaçados pelas constantes investidas do mercado as quais colocam os interesses fundiários, imobiliários, comerciais e financeiros acima daqueles inerentes à promoção da igualdade e justiça.

\section{Referências}

BRANDÃO, Robson José Alves. A última fronteira do bioma cerrado: análise da natureza da expansão do agronegócio no Oeste da Bahia. Dissertação (Mestrado em Desenvolvimento e Meio Ambiente) Universidade Federal de Pernambuco, Recife, 2017.

CASTILHO, Cláudio Jorge Moura de. O uso neoliberal do espaço - impactos sobre os "territórios da vida humana" na cidade. Revista Okara: Geografia em Debate, v. 13, n. 2, p. 597-623, 2019.

CASTILHO, Cláudio Jorge Moura de. Territórios violados, resistências e massacres de povos e pobres na história do Brasil - mas a luta continua. Boletim Goiano de Geografia, v. 4, p. 1-25, 2020.

COLTURATO, Andriel Rodrigo e MASSI, Luciana. Aportes teóricos e metodológicos para a história da ciência com base no materialismo histórico-dialético. Germinal: Marxismo e Educaşão em Debate, Salvador, v. 11, n. 3, p. 170-180, 2019.

FREIRE, Paulo. Pedagogia do oprimido. São Paulo: Paz e Terra, 2019 [1972].

GRAMSCI, Antonio. Os intelectuais e a organização da cultura. Rio de Janeiro: Editora Civilização Brasileira, 1989.

HARVEY, David. A brief history of neoliberalism. London: Oxford University Press, 2005.

HARVEY, David. A loucura da razão econômica. Marx e o capital no século XXI. São Paulo: Boitempo, 2018. 
HARVEY, David. Os limites do capital. São Paulo: Boitempo, 2013.

LEFEBVRE, Henri. Le droit à la ville. Paris: Éditions Anthropos, 1968.

MARX, Karl e ENGELS, Friedrich. Manifesto do partido comunista. Rio de Janeiro: Editora Cátedra, 1987 [1847].

MARX, Karl. A guerra civil na França: mensagem do Conselho Geral da Associação Internacional dos Trabalhadores. São Paulo: Global, 1986 [1891]. (Coleção bases, 50)

MARX, Karl. O dezoito brumário de Louis Bonaparte. São Paulo: Editora Moraes, 1987 [1852].

PONTE, Bruno Augusto Nogueira Monteiro. Desenvolvimento e governança ambiental: em busca de uma outra práxis na dinâmica territorial da "Reserva" do Paiva-PE. Dissertação (Mestrado em Desenvolvimento e Meio Ambiente) - Universidade Federal de Pernambuco, Recife, 2017.

RIBEIRO, Darcy. O povo brasileiro: a formação e o sentido do Brasil. São Paulo: Global, 2015.

SANTOS, Milton e SILVEIRA, María Laura. O Brasil. Território e sociedade no início do século XXI. Rio de Janeiro: Record, 2001.

SANTOS, Milton. A natureza do espaço. Técnica e tempo. Razão e emoção. São Paulo: Hucitec, 1997.

SANTOS, Milton. O espaço do cidadão. São Paulo: Nobel, 1987.

SANTOS, Milton. Por uma outra globalização. Do pensamento único à consciência universal. Rio de Janeiro: Record, 2000.

SOUZA, Jessé. A elite do atraso. Da escravidão à lava jato. Rio de Janeiro: Leya, 2017.

\section{Notas:}

${ }^{1}$ Professor do Departamento de Ciências Geograficas e do Programa de Pós-graduação em Desenvolvimento e Meio Ambiente UFPE Bolsista N1-D do CNPq. Orcid: http:/ / orcid.org/0000-0003-3609-9914 E-mail: claudiocastilho44@gmail.com

2 Obras de pensadores que, para nós, constituem novos intelectuais do quilate, por exemplo, de Paulo Freire e Boaventura de Souza Santos aprofundaram de maneira magistral essa discussão, razão pela qual não se estenderá a discussão.

${ }^{3}$ Entrevistas realizadas nos primeiro e segundo semestres do ano de 2019.

Recebido em: 16.06 .2020

Aprovado em: 11.09.2020 